\title{
FOUNDATION FOR NETWORKING: A THEORETICAL VIEW ON THE VIRTUAL ORGANIZATION
}

\author{
Jens Eschenbaecher \\ BIBABremen,esc@biba.uni-bremen.de \\ Sonja Ellmann \\ BIBA Bremen, ell@biba.uni-bremen.de \\ GERMANY
}

\begin{abstract}
This paper is an attempt to explain the important impacts that organisation theory delivers with respect to the concept of virtual organisation. The authors believe, that not enough research has been conducted in order to transfer theoretical foundations for networking originating from economics or social sciences to the phenomenon of virtual organisations. However, a strong theoretical foundation of widely accepted approaches is necessary in order to justify and understand the profitability of virtual organisations. This foundation, built upon a solid infrastructure provided through information and communication technology, will result in a better understanding of collaborative structures in general and virtual organisations in particular.
\end{abstract}

\section{INTRODUCTION}

Progress in information and communication technology (ICT), paired with globalisation and increased networking have smoothed the way into a new business era and called for new proposals of doing business. Advanced management- and integration systems that support and simplify (collaborative) business processes in and between enterprises are available nowadays (such as SCM, CRM, ERP II systems, EDI, EAI and Web Services). This new architecture has called for a process of re-thinking on an organisational level: Innovation in organisation theory has its roots in innovative developments in ICT. The ICT architecture, on the other hand, is completed and applied to real world situations through findings from organisation theory and theoretical foundations.

"The next-generation Internet is about much more than high-speed networks-the real issue is not what the technology can do, but what we can do with it", (Ladid, 2000). This quote underlines, that recent developments are built upon a solid ICT infrastructure but yet have to be accompanied by new organisational models, such as the Virtual Organisation (VO). These models have to be explained and made transparent through theory. While keeping in mind that VOs are only explainable through multidisciplinary approaches (connecting social sciences, economics, engineering, business and legal issues), this paper examines socio-economic and organisational approaches. The authors believe, that not enough contribution for the explanation of VOs has been 
provided from those areas. Most theoretical foundations for the VO can still be found in engineering (Warnecke, 1992; Bullinger et al, 1995).

In the proceeding, an overview about most frequently mentioned concepts in network studies, their main characteristics and the context of their appearance will be provided. The most important and sustainable concepts are explained in more detail and their significance with respect to providing a profound theoretical foundation for VOs will be examined. A conclusion is derived from the theoretical models in form of statements about characteristic features of the predominant form of organisation in future.

\section{THEORETICAL FOUNDATIONS FOR NETWORKING}

A VO is a temporary network of companies. Potential partners come together to quickly exploit fast-changing opportunities. A VO is put together of a set of cooperating (legally) independent organisations, which provide services and functionality to the outside world as if they were one organisation. It can thus be seen and managed as if it was a single organisation (Sydow, 1996; Byrne 1993).

A large amount of approaches on networking has been published in articles and books. Nohria finds the right words to describe this scenario: "Anyone reading through what purports to be network literature will readily perceive the analogy between it and a "terminological jungle in which any newcomer may plant a tree", (Nohria, 1992). Each approach highlights different facets of networking and they are therefore, taken as a whole, completing one another. The limited scope of this paper allows for the examination of six approaches. (Oliver, Ebers, 1998) and (Sydow, 1992) have reviewed and organised the vast literature on networking theories and developed a state-of-the-art of research on inter-organisational relations and networks.

About twenty different approaches have been surveyed for this paper (among them the principal agent approach, which has been excluded because of the inherent assumption of asymmetric information, furthermore industrial marketing, the strategy approach, the institutional approach and others. For further material, please contact the authors or compare Oliver, Evers, 1998 and Sydow, 1992). In the end, those approaches have been selected, that provide the most important contributions for the theoretical foundation of collaborative processes in general and the VO in particular with respect to three dimensions: (1) Regarding the reasons for development of VOs with respect to the cost and resource side, transaction cost theory and resource dependence theory provide important insights. (2) The evolutionary side of development is covered through population ecology and game theory. (3) The historical development is explained through the industrial cluster approach. (4) Finally, network theory provides a basic approach for the understanding of the complex phenomenon of networks as such.

\subsection{Transaction Cost Approach}

Oliver E. Williamson (1985) suggested that transaction-cost economics provides a model to help explain varieties of organisational forms. Central object of analysis in 
this approach is the transaction, which includes the exchange of goods, services and disposal rights (Ebers, Gotsch, 1993).

All in all, seven different factors influence transaction costs: (1) Finding a customer (2) establishing (3) negotiating (4) monitoring (5) coordinating (6) maintaining the relationship or contract between team members. Furthermore, (7) the fear of supplier opportunism plays an important role (Jarillo, Stevenson, 1991). Costs thus mainly consist of information and protection (against opportunistic behaviour) costs. Transaction costs increase, whenever transaction takes place infrequently and uncertainty is high. Economic subjects have the choice between make-or-buy-or-corporate decisions. Because the total of cost increasing factors determines the amount of transaction costs, transaction costs are important in order to find the right strategy for cooperation. Every investment that is necessary for a reduction of insecurities will increase transactions costs. The more complex a situation is, the higher those costs will be (Mayer, 2000).

The transaction cost approach is valuable in order to understand the extremes of market (which makes sense in case of low insecurity, low transaction-specific investment and low frequency) and hierarchy (justifiable whenever insecurities and transaction specific investments are very high) and their mutual failure which leads to the development of hybrid forms - such as VOs - in order to optimise production and transaction costs: In VOs, exchange is expanded beyond organisational boundaries. Communication can take place in a similar way inside and out of the organisation. Therefore, transaction inside the organsiation and between organisations makes no difference. A VO is thus efficient internally and provides external flexibility and strives therefore for an optimisation of transaction and production costs (Varamäki, Pihkala, 1997).

\subsection{Resource Dependence Theory}

The resource-based view concentrates on the use of internal and controllable resources: A single organisation can ususally not have all necessary resources at its disposal. This is the predominant reason according to this approach, why cooperation makes sense and might even be inevitable. In that framework, organisations try to minimise their own dependencies, while maximising those of others (Pfeffer, Salancik 1978). The dependency of one organisation towards another one is increasing proportionally with the resource dependence. Superior goal is the mutual exchange of resources. It is therefore advisable for an organisation to specialise on core competencies and to outsource all futile activities. This is exactly what virtual organising is about: Member firms have to be able to offer unique resources or operations that are applicable outside the firm and which benefit the whole network. Primary value adding element of a VO is then the joint capability by means of which partners change competencies into profitable operation (Varamäki, Pihkala, 1997). 


\subsection{Evolutionary Approaches I: Population Ecology}

Population ecology has its theoretical origin in Darwin's biological population ecology and was transferred to organisation theory by Hannan and Freeman in 1977.

Superior goal of population ecology is to find out, why some forms of organisations succeed, while others only last for a short time. Populations are communities of organisations that have a common fate with respect to environmental variables. The environment is seen as insecure and dynamic, which makes it an abstraction of the current situation: The new economy is characterised through global markets and increased competition, highly dynamic environments, customer driven-markets, availability of new technologies, networked environments and demand for extended products (for more information on extended products: Thoben et al, 2001). Population ecology suggests, that a diversity of organisational forms exists, but in the end, only the one that is optimally adapted to its environment will survive (Hannan, Freeman, 1977). Indicator of success is the netto rate of reproduction, meaning that a successful organisation is able to survive and also to spread (Mayer, 2000).

Variation, selection, and reproduction explain the development, existence and success of VOs. Triggers for large-scale population specific changes can be new technologies or changes in institutional context according to (Hannan, Freeman, 1977). This statement is transferable to the new economy: Changes in technology (Internet, innovative management systems) and environment (global market places, increased networking) have called for flexible, dynamic and ICT-driven organisations that can easily adapt to changing requirements. The VO epitomises exactly these conditions. The degree of flexibility regarding choice of partners is very high. Dynamic changes in partner constellation are co-ordinated through a broker and depend upon the specific order (compare e.g. Virtuelle Fabrik, www.virtuelle-fabrik.ch).

\subsection{Evolutionary Approaches II: Evolutionary Game Theory}

Evolutionary game theory has two major approaches- the Hawk-Dove game, in which two individuals compete for a resource of a fixed value and in which each individual follows exactly one of two strategies. However, for the explanation of cooperation, the second approach- the prisoner's dilemma- is more interesting:

Two players can choose between the strategies to co-operate and not to cooperate. If both co-operate, they would get a better result, as if both defect. The highest value can be reached for the player that defects (and thus exploits the other player), while the other co-operates. The players don't know which strategy the other player will choose and therefore, in the originial game, a pareto-inferior strategy of non-cooperation will be the result. If game theory is extended and more than one round is played, interesting results can be extracted for the understanding of VOs. Games, that are played for several rounds, provide continuous dynamics and comprise a replicator mechanism. Research efforts have proven, that if several rounds are played, a strategy called tit-for-tat succeeds: Players start with cooperation and do, whatever the other player did in the previous round (Axelrod, 1984). In this new scenario, cooperation becomes attractive: The player has a chance for revenge, if he was exploited in the precedent round. The game has an inherent 
sanctioning mechanism. On the other hand, there is also a strong incentive for cooperation through the nature of the game: Cooperation will lead to beneficial and pareto-optimal results, because the pay-off for mutual cooperation is higher than that for mutual defect. In a world of tit-for-tat, other potential network partners will soon get to know, which partners are serious and reliable and which are not. Potential partners that have defected once, will not be accepted in another network formation. This will result in an exclusion from the breeding environment, the pool in which VOs form (Camarinha-Matos, Afsarmanesh, 2003 and network approach, 2.6.). In the current dynamic, fast changing and customer-demand driven environment, it is crucial for companies to have partners with whom they can work together in order to fullfill customer demand. Information technology has led to increased transparency and following from that, information about potential partners is easily accessible and processable.

\subsection{Industrial Cluster}

An industrial cluster is a set of industries related through buyer-supplier and supplier-buyer relationships, or by common technologies, common buyers or distribution channels, or common labour pools (Porter 1990). This cluster can be regional, which means that member firms have a close geographical proximity (Enright, 1992). Hence, cluster theory suggests, that certain connections between enterprises might lead to the development of closer collaboration. Industrial districts (such as the Italian industrial districts described e.g. in Brusco 1992; Piore, Sabel 1984) are concentrations of firms involved in interdependent production processes, often in the same industry or industry segment. With respect to globally distributed partners, Wagner and Mirtschink introduce the notion of a virtual cluster: The idea is to transfer the concept of a regional cluster into virtual space (Wagner, Mirtschink, 2003). Cluster approaches are especially important for understanding the historical development of VOs: Enterprises without former collaboration experience are certainly not getting beyond simple forms of collaboration, such as buy-sell. For complex projects, however, a certain level of trust between participants is crucial. Achieving trust is a process that takes time. Clusters thus provide some kind of "pool" of potential partners. Certain knowledge about the partners exists, because they aren't complete strangers. The authors therefore believe that clusters are a special form breeding environment (compare Camarinha-Matos, Afsarmanesh, 2003 and network approach, 2.6) for the further development of VOs. After assessing advantages of a potential collaboration, cluster members might decide to co-operate in form of VOs. The risk of exploitation is low, because partners have knowledge about each other.

\subsection{Network Approach}

Central question of the network approach is, how interactions between individuals, groups and institutions take place and to give explanations for explicit behaviour (e.g. Powell, 1990, Burt, 1980). Composition of networks and role allocation in networks are the main objects of analysis. The entirety of economic exchange processes between organisational units is analysed from a holistic perspective (Mayer, 2000). Similar to resource dependence theory, one unit has to get resources 
from other units in order to achieve its own goals. Dependencies of different strength hence develop. Trust is very important in network theory, because it reduces the need for formal contracts and thereby transaction costs (Varamäki, Pihkala, 1997). Participants of virtual networks need to trust each other, otherwise the network would cease to exist or not even develop. In this context, (CamarinhaMatos, Afsarmanesh 2003) underline the importance of environments for the dynamic formation of VOs (they call those environments virtual breeding environments). Nelson and Winter, adherents of the dynamic network approach, underline the importance of management of a network through a broker (Nelson, Winter, 1982). The existence of a broker is a crucial condition in VOs.

\section{DISCUSSION AND ELABORATION OF THE FINDINGS}

The discussion of the most influential explanations for inter-organisational relationships in chapter two makes clear, that no single theoretical model is able to describe the complex phenomenon of VO entirely and to clarify knowledge deficits. Rather, different models are able to explain certain facts or fragments of the whole complex of inter-organisational networks such as VOs (Mayer, 2000; Piber, 2000).

Figure 1 outlines the contributions of the selected theoretical approaches in order to explain the existence of VOs. The three dots on each side symbolise the coexistence of other approaches.

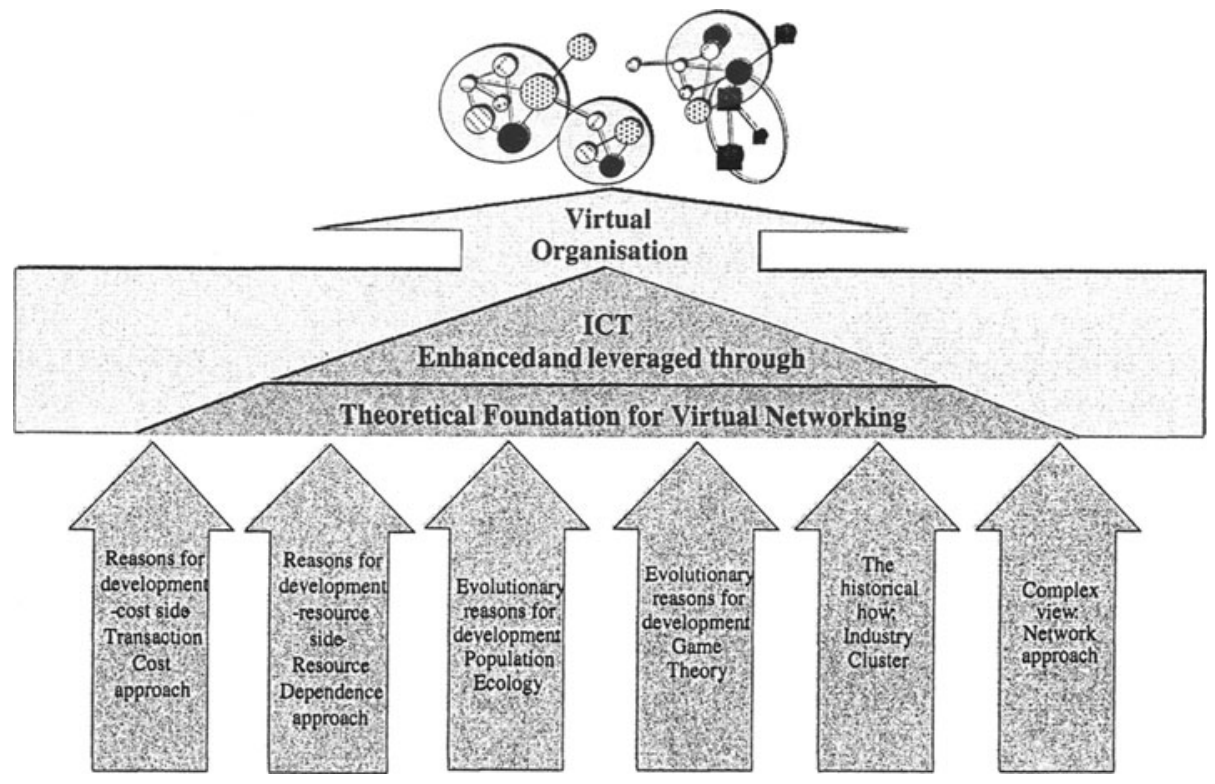

Figure 1- Theoretical foundation for virtual organisations

It is now possible to derive specific meaningful hypothesis for VOs from the six depicted approaches. In order to understand the current trend towards virtual 
networking, again, it is important to merge the theoretical framework with the overall enabler for innovative forms of networking: Recent developments in ICT.

Hypothesis 1: Potential partners need to see a transaction cost advantage in order to participate in a VO. If transaction costs are lower than production costs, participation in a VO will be aspired. Whenever insecurity about a transaction increases or transaction specific investments become important, VOs are attractive.

Hypothesis 2: Firms that participate in VOs can offer a core competency, at which they excel and that is valuable to other participants. Win-win situations require, that each partner has an interest in the other partner's resources.

Hypothesis 3: VOs are organisational forms that are well-adapted to current economic circumstances. They inherently and through definition fulfil the requirements of dynamic, customer driven, ICT supported environments.

Hypothesis 4: In a world of high transparency, irreliable partners are easily discernible. Game theory suggests, that even in temporary formations, such as VOs, it is worthwhile being a trustworthy collaboration partner, especially under consideration of the phenomenon of virtual breeding environments.

Hypothesis 5: The existence of clusters provides and environment of trust. The development of VOs is thereby simplified.

Hypothesis 6: It is crucial, that participants share a common goal and see the network relationships as advantageous in order to reach that goal. A broker is responsible for co-ordination in VOs. Trust is crucial in VOs in order to reduce the need for formal contracting.

As outlined before, this paper provides a socio-economic and organisational perspective that is derived from the examined approaches. Yet, in order to provide an overall view regarding $\mathrm{VO}$ it is important, to address legal issues (see for example Eschenbaecher et al, 2001 or eLEGAL, http://cic.vtt.fi/projects/elegal/ public.html), to highlight the importance of early and open standards (see for example C-ECOM initiative, http://www.cenorm.be/isss/Projects/c-ecom/default. $\mathrm{htm}$ ) and to address human related issues, such as training and habituation to collaborative scenarios. This paper is only able to cover a segment and has to be seen in a context with research approaches that cover other areas. The authors work on a holistic picture about the environment and influencing factors of VO, but because of the limited scope of this paper, only a fragmented view can be provided.

\section{CONCLUSION}

This paper underlines the impact of selected theoretical approaches for the explanation of VOs. Theory proves, that VOs have the potential to satisfy current requirements for dynamic and agile manufacturing, extended products and increased customer demand in an optimised way. Theoretical considerations are leveraged through the state-of-the-art in available technology and this combination suggests VOs as one potential optimal outcome. The theoretical foundation derived in figure 1 represents a first attempt to structure the main facets of $\mathrm{VO}$ in a common model. The authors are open for feedback to further discuss and refine this structure. 


\section{REFERENCES}

1. Axelrod, R. The Evolution of Cooperation. New York: Basic Books, 1984.

2. Bullinger, H., Brettreich-Teichmann, W., Fröschle, H.-P. Das virtuelle Unternehmen: Koordination zwischen Markt und Hierarchie. Office Management 1995; 43 (12): 18-46.

3. Brusco, S. "The idea of the Industrial District: Its genesis". In Industrial Districts and Inter-firm Cooperation in Italy, F. Pyke et al, eds. Geneva: International Institute for Labour Studies, 1992.

4. Burt, R.S. Models of Network Structure. Annual Review of Sociology 1980; 6: 79-141.

5. Byrne, J. The Virtual Corporation. Business Week, 1993; 8: 37-41.

6. Camarinha-Matos, L.M., Afsarmanesh, H. Elements of a base VE infrastructure. J. Computers in Industry, Vol. 51, Issue 2, Jun 2003, pp. 139-163.

7. C-ECOM, Cluster for Electronic COMmerce: http://www.cenorm.be/isss/Projects/c-ecom/default.htm; last access 24.06. 2003

8. Enright, M. J. Why Local Clusters are the Way to Win the Game. World Link 1992; 5: 24-25.

9. Ebers, M., Gotsch, W. "Institutionenökonomische Theorien der Organisation". In Organisationstheorien, A, Kieser, ed. Stuttgart: Kohlhammer, 1993.

10.eLEGAL, Specifying Legal terms of Contract in ICT Environments: http://cic.vtt.fi/projects/elegal/ public.html; last access 24.06.2003.

11. Eschenbaecher, J., Kulck, N., Weiser, B. "Business and legal issues in enterprise collaborations: a German perspective". In International Journal of Production Planning \& Control, 2001; 12 (5): 488-503.

12. Hannan, M.T., Freeman, J.H. The population ecology of organizations. American Journal of Sociology 1977; 82: 929-964.

13. Jarillo, J.C., Stevenson, H. Cooperative Strategies-The payoffs and the Pitfalls. Long Range Planning 1991; 1: 64-74.

14. Ladid, L. Ipv6-The new-generation Internet. Ericsson Review 1, 2000.

15. Mayer, A.G. Strategische Unternehmensnetzwerke und Marketing. Aufbau und Management von marktorientierten strategischen Interorganisationsbeziehungen. Regensburg: Roderer Verlag, 2000.

16. Nelson, R.R., Winter, S.G. An Evolutionary Theory of Economic Change. Cambridge, MA: Cambridge Uniersity Press, 1982.

17. Nohria, N. "Is a network perspective a useful way of studying organizations"? In Networks and organizations: Structure, form, and action, N. Nohria, R.G. Eccles, eds. Boston, MA: Harvard Business School Press, 1992.

18. Oliver, A.L., Ebers, M. Networking Network Studies. Organization Studies 1998;19 (4): 549-583.

19. Pfeffer, J. and Salancik, G.R. The external control of organizations: A Resource Dependence Perspective. New York: Harper and Row, 1978.

20. Piber, M. Die integrierte Organisation- Ein dreidimensionales Modell zum Management kooperativer Unternehmensnetzwerke. Frankfurt a.M., Berlin et al: Peter Lang, 2000.

21. Piore, M. and Sabel, C. The Second Industrial Divide. New York: Basic Books, 1984.

22. Porter, M.E. Competitive Strategies: Techniques for Analysing Industries and Competitors. New York: Free Press, 1980.

23. Powell, W.W. "Neither Market nor Hierarchy: Network Forms of Organiszation". In Research in Organizational Behavior: An Annual Series of Analytical Essays and Critical Reviews, B. M. Staw, L. L. Cummings eds. Greenwich, London: JAI Press 1990; 12: 295-336.

24. Sydow, J. Strategische Netzwerke: Evolution und Organisation. Wiesbaden: Gabler, 1992

25. Sydow, J. Virtuelle Unternehmung: Erfolg als Vertrauensorganisation? Office Management 1996; 44 (7-8): 10-13.

26. Thoben, K.-D., Jagdev, H., Eschenbaecher, J.: Extended Products: Evolving Traditional Product concepts. Proceedings of the 7th International Conference on Concurrent Enterprising: Engineering the Knowledge Economy through Co-operation. Bremen, Germany 27-29 ${ }^{\text {th }}$ June 2001: 429-439.

27. Varamäki, E., Pihkala, T.: A hotel of small firms-An oddity of SME-networking. In Journal of Best Papers Proceedings, ICSB Conference, San Francisco, 1997.

28. Virtuelle Fabrik. www.virtuelle-fabrik.ch, last access 24.06.2003.

29. Wagner, K., Mirtschink, D. TRUST: Einsatz von Wissenstechnologie bei wissensintensiven Problemlöse-prozessen im virtuellen Automobil-Cluster.

http://www.knowtech2002.de/Wagner_IAO_Stuttgart_Mirtschink.pdf; last access 24.06.2003.

30. Warnecke, H.J. Die fraktale Fabrik. Berlin: Springer Verlag, 1992.

31. Williamson, O. The Economic Institutions of Capitalism. New York: The Free Press, 1985. 